\title{
QuEChERS - UM MÉTODO MODERNO DE PREPARO DE AMOSTRA PARA DETERMINAÇÃO MULTIRRESÍDUO DE PESTICIDAS EM ALIMENTOS POR MÉTODOS CROMATOGRÁFICOOS ACOPLADOS À ESPECTROMETRIA DE MASSAS
}

\author{
Osmar D. Prestes, Caroline A. Friggi, Martha B. Adaime e Renato Zanella* \\ Departamento de Química, Universidade Federal de Santa Maria, 97105-900 Santa Maria - RS, Brasil
}

Recebido em 9/9/08; aceito em 21/1/09; publicado na web em 28/7/09

\begin{abstract}
QuEChERS - A MODERN SAMPLE PREPARATION METHOD FOR PESTICIDE MULTIRESIDUE DETERMINATION IN FOOD BY CHROMATOGRAPHIC METHODS COUPLED TO MASS SPECTROMETRY. This review attempts to provide an updated overview of the Quick, Easy, Cheap, Effective, Ruged and Safe (QuEChERS) multiresidue extraction method, that involves initial extraction in acetonitrile, an extraction/partition step after the addition of salt, and a cleanup step utilizing dispersive solid phase extraction. QuEChERS method is nowadays the most applied extraction method for the determination of pesticide residues in food samples, providing acceptable recoveries for acidic, neutral and basic pesticides. Several applications for various food matrices (fruits, vegetables, cereals and others) in combination with chromatographic mass spectrometry analysis were presented.
\end{abstract}

Keywords: QuEChERS method; food analysis; pesticides.

\section{INTRODUÇÃO}

No mundo, as perdas anuais devido à ação de pragas na agricultura chegam a 1 bilhão de toneladas, correspondendo a uma redução de 20 a $30 \%$ na produção. Os pesticidas, desde seu desenvolvimento, desempenharam um importante papel no crescimento da agricultura moderna. A utilização destes compostos químicos, que por um lado gera benefícios, por outro, é responsável pela contaminação do solo, água e alimentos. ${ }^{1}$ Assim, a determinação de resíduos de pesticidas em alimentos e em amostras ambientais é importante devido ao risco que estes compostos oferecem à saúde humana, além da sua persistência no meio ambiente e tendência de bioacumulação. Nas últimas décadas, laboratórios públicos e privados vêm desenvolvendo métodos para a determinação de resíduos de pesticidas, principalmente em alimentos. Contudo, a maioria dos métodos oficiais de análise está longe do considerado ideal, ou seja, métodos de ampla aplicação, rápidos, sensíveis e com resultados confiáveis. ${ }^{2}$

A determinação de resíduos de pesticidas desempenha um papel importante para a estimativa da exposição humana e do meio ambiente a estes compostos, permitindo avaliar a conformidade da produção agrícola com as Boas Práticas Agrícolas, possibilitando decisões regulatórias comerciais visando garantir a segurança alimentar. Atualmente, ações governamentais e também do setor privado, estabelecem uma maior importância para a análise de resíduos de pesticidas, sendo que há uma pressão crescente para o aperfeiçoamento do desempenho analítico, exigindo aumento da eficiência e diminuição do custo e do tempo das análises. ${ }^{3}$

Produtos agrícolas como frutas, vegetais e cereais são as matrizes mais analisadas em laboratórios de rotina, apresentando frequentemente resíduos de pesticidas de diversas classes. Assim, é de fundamental importância o desenvolvimento de métodos multirresíduo de pesticidas para a determinação nestes tipos de alimentos. A diferença das propriedades químicas entre estes compostos e a diversidade de matrizes são algumas das adversidades a serem contornadas no desenvolvimento destes métodos, os quais frequentemente apresentam etapas laboriosas que demandam tempo, grande custo de material e geram grandes quantidades de resíduos tóxicos. ${ }^{4}$

\footnotetext{
*e-mail: rzanella@base.ufsm.br
}

Neste trabalho de revisão apresentamos informações sobre o método de preparo de amostra denominado QuEChERS (Quick, Easy, Cheap, Effective, Rugged, Safe), proposto em 2003 por Anastassiades et al., ${ }^{5}$ as modificações do procedimento original descritas na literatura e as aplicações deste método na área de alimentos empregando métodos cromatográficos acoplados à espectrometria de massas.

\section{Preparo de amostra de alimentos para análises de resíduos de pesticidas}

A determinação de resíduos de pesticidas, devido às concentrações dos analitos serem geralmente muito baixas, apresentarem propriedades químicas distintas, bem como a complexidade das matrizes, faz com que ocorra a necessidade de uma etapa prévia de preparo da amostra. Devido ao fato de que as medidas são normalmente efetuadas em baixos níveis de concentração, as interferências são problemas frequentes que devem ser considerados. Os principais objetivos do preparo da amostra são, portanto, promover a extração e o enriquecimento dos analitos de interesse, e a remoção, tanto quanto possível, dos interferentes. Perdas de analito nesta etapa podem comprometer o resultado das análises. Desta maneira, o preparo da amostra é uma etapa crucial dentro de todo o processo analítico. ${ }^{6,7}$

Nos últimos anos, ocorreu um rápido desenvolvimento de novos métodos analíticos, para a determinação de resíduos de pesticidas em produtos agrícolas. Geralmente, a complexidade da matriz destes produtos ocasiona dificuldades para a quantificação dos pesticidas, sendo necessária a realização de uma etapa de purificação (clean-up) do extrato, após extração com solvente. ${ }^{8}$ Essa etapa é fundamental, uma vez que reduz as interferências e o efeito-matriz, além de diminuir a necessidade de manutenção do sistema cromatográfico. ${ }^{9}$ No sentido de melhorar a análise quantitativa, esforços foram realizados no desenvolvimento de novos métodos de extração e clean-up..$^{10,11}$

O primeiro método multirresíduo para extração de pesticidas foi desenvolvido por Mills et al. na década de 1960, nos laboratórios do U.S. Food and Drug Administration (FDA). ${ }^{12} \mathrm{O}$ método baseia-se em uma extração com acetonitrila $(\mathrm{MeCN})$ sendo utilizado basicamente na determinação de compostos organoclorados apolares em amostras não-gordurosas. A adição de água ao extrato, seguida de uma etapa subsequente de partição, promovida através da adição de solventes 
apolares (etér de petróleo ou hexano). Além de água, açúcares e sais também são removidos do extrato nesta etapa. ${ }^{13,14}$

O desenvolvimento e aplicação de pesticidas com características mais polares, como por exemplo, organofosforados e organonitrogenados, demandou novos métodos de extração multirresíduo que englobassem estes compostos. ${ }^{15}$ Em 1975, Luke et al. desenvolveram o denominado método de Luke, que consiste em uma etapa de extração de $100 \mathrm{~g}$ de amostra utilizando acetona $(200 \mathrm{~mL})$, seguida de uma partição líquido-líquido com solventes apolares (éter de petróleo e diclorometano), sendo utilizados $100 \mathrm{~mL}$ de cada. ${ }^{16}$ Com o objetivo de obter-se maiores percentuais de recuperação para os compostos polares, adicionou-se cloreto de sódio $(\mathrm{NaCl})$ na fase aquosa para favorecer a transferência destes para a fase orgânica..$^{13,14}$

Krijgsman et al. ${ }^{17}$ com o intuito de melhorar os resultados obtidos com o método de Luke, propuseram a extração de pesticidas utilizando acetato de etila com subsequente adição de sulfato de sódio anidro, obtendo maior rapidez, simplicidade, limpeza dos extratos e melhores valores de recuperação para os compostos polares, quando comparado ao método de Luke. A imiscibilidade do sistema acetato de etila - água tornou desnecessária a adição de solventes apolares. Todas estas vantagens fizeram deste o método oficial para extração multirresíduo de pesticidas em vários países europeus. Uma das desvantagens deste método é a quantidade de co-extrativos apolares tais como, lipídios e ceras, tornando necessária uma etapa posterior de clean-up utilizando cromatografia por permeação em gel $(\mathrm{Gel}$ Permeation Chromatography, GPC), aumentando significativamente o tempo e o custo do preparo da amostra. ${ }^{13}$

Na década de 1980, o Food and Consumer Product Safety Authority da Holanda desenvolveu em seu laboratório o método de extração mini-Luke, o qual é uma miniaturização do método de extração Luke original, omitindo-se a etapa de particionamento com cloreto de sódio. O método consiste na extração de $15 \mathrm{~g}$ de frutas ou vegetais já processados, adicionando-se acetona $(30 \mathrm{~mL})$ seguida de agitação em homogeneizador Ultraturrax por cerca de $30 \mathrm{~s}$, sendo posteriormente adicionados éter de petróleo $(30 \mathrm{~mL})$ e diclorometano $(30 \mathrm{~mL})$, agitando-se novamente por cerca de $30 \mathrm{~s}$. A miniaturização deste método possibilitou a redução da quantidade de amostra, bem como de solventes utilizados. Entretanto, valores baixos de recuperação $(<70 \%)$ foram obtidos para pesticidas polares, como metamidofós, ometoato, monocrotofós entre outros. Como um método de extração alternativo, desenvolveu-se no VWA uma modificação do método de extração mini-Luke nos anos 90, onde foi adicionado sulfato de sódio anidro na etapa de extração levando, assim, a uma melhor extração dos pesticidas polares..$^{18}$

Durante os anos 1990, devido às fortes pressões de ambientalistas e também a fatores relacionados à saúde humana, ocorreu um grande desenvolvimento de métodos alternativos de extração baseados na redução do volume de solvente utilizado na etapa de extração. ${ }^{19-21}$ Entre estes novos métodos podemos citar a extração em fase sólida (Solid Phase Extraction, SPE), ${ }^{22}$ a qual também tem sido empregada com frequência na etapa de purificação do extrato para amostras de alimentos. ${ }^{23,24}$ Outros métodos que foram desenvolvidos neste período também tinham como objetivo a simplificação de etapas como, por exemplo, dispersão da matriz em fase sólida (Matrix Solid Phase Dispersion, MSPD) e microextração em fase sólida (Solid Phase Micro Extraction, SPME).$^{25,26}$ Em 1999, foi proposta a extração sortiva em barra magnética (Stir Bar Sorptive Extraction, SBSE), ${ }^{27}$ que fornece baixos limites de detecção (Limit of Detection - LD), especialmente para analitos hidrofóbicos. ${ }^{28}$ Extração por fluido supercrítico (Supercritical Fluid Extraction, SFE) ${ }^{29}$ extração acelerada por solventes (Pressurized Liquid Extraction, PLE) e extração assistida por micro-ondas (Microwave Assisted Extraction, MAE) são exemplos de métodos que apresentam, ${ }^{30,31}$ dentre outras características, elevada eficiência, entretanto geralmente demandam investimento considerável em instrumentação. Estes novos métodos que têm como base a instrumentação, sendo a extração muitas vezes automatizada, demandam analistas treinados e etapas de limpeza entre extrações, o que implica em um maior tempo de análise. Outra desvantagem geralmente apresentada é o escopo limitado de pesticidas que podem ser extraídos sob determinadas condições. Sendo assim, estes procedimentos,podem ser empregados em algumas aplicações, mas estão distantes de serem considerados ideais para um método multirresíduo. ${ }^{32}$

De acordo com Hercegová et al. um método multirresíduo de preparo de amostra para análise de pesticidas deve apresentar as seguintes propriedades: incluir o maior número de pesticidas possíveis, recuperações próximas a $100 \%$, remover os possíveis compostos interferentes da amostra, boa precisão e robustez, baixo custo, rapidez, facilidade e segurança (utilizar pequenos volumes de solventes de baixa toxicidade) ${ }^{6}$

\section{DESENVOLVIMENTO DO MÉTODO QuEChERS ORIGINAL}

Em 2003, Anastassiades et al. com o objetivo de superar limitações práticas dos métodos multirresíduo de extração disponíveis na época, introduziram um novo procedimento de preparo de amostras para extração de resíduos de pesticidas denominado QuEChERS, sendo que a pronuncia deve ser "catchers". ${ }^{5,33,34}$ Esse método, que tem como vantagens ser rápido, fácil, econômico, efetivo, robusto e seguro, explora as possibilidades oferecidas pela instrumentação analítica moderna. Durante o seu desenvolvimento, grande ênfase foi dada para a obtenção de um procedimento dinâmico, que pudesse ser aplicado em qualquer laboratório, devido à simplificação das etapas como representado no fluxograma da Figura 1.

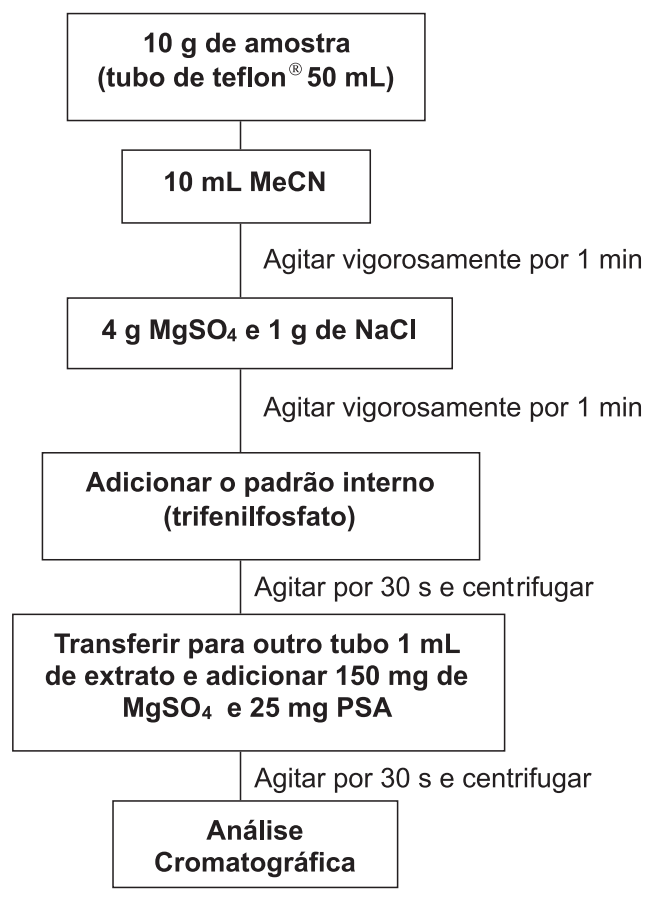

Figura 1. Fluxograma representativo do método QuEChERS original

\section{Tamanho da amostra}

Para garantir de maneira simples uma maior eficiência do procedimento de preparo de amostra, usualmente, é utilizada a menor quantidade possível de amostra, desde que esta garanta representativi- 
dade estatística ao resultado final. ${ }^{5}$ De maneira geral, amostras sólidas, como a maioria dos alimentos, requerem etapas mais complexas e demoradas durante seu preparo. ${ }^{35,36}$ Uma das possibilidades de obterse amostras sólidas homogêneas é através do corte das amostras em pedaços menores seguido de processamento em homogeneizadores. ${ }^{6}$ Fussel et al. demonstraram que a realização desta etapa à temperatura ambiente pode provocar a perda de alguns analitos como, por exemplo, bitertanol, heptenofós, isofenfós e tolilfluanida. ${ }^{37}$ Baseado em dados da literatura, a quantidade de amostra escolhida no desenvolvimento do método QuEChERS foi de $10 \mathrm{~g},{ }^{5}$ sendo esta considerada ideal quando comparada a quantidades de 15 a 100 g normalmente utilizadas em outros métodos multirresíduo. ${ }^{38-40}$

\section{Escolha do solvente de extração}

A seleção do solvente de extração é um dos pontos fundamentais no desenvolvimento de um método de extração multirresíduo. Muitos aspectos devem ser considerados, entre eles: habilidade de extração de um amplo espectro de pesticidas com diferentes polaridades, apresentar seletividade durante a extração, partição e clean-up, compatibilidade com diferentes técnicas cromatográficas, baixo custo, segurança, além de observar a legislação ambiental. ${ }^{41}$

Os solventes mais utilizados para extração multirresíduo de pesticidas são: acetato de etila, acetona e acetonitrila, sendo que cada um destes apresenta vantagens e desvantagens. Acetato de etila tem demonstrado ser um solvente com características universais, uma vez que possui capacidade para extrair pesticidas de diferentes classes em diversos tipos de amostras, porém os percentuais de recuperação de pesticidas com caráter básico $(\mathrm{pKa}>4)$ são baixos devido a problemas de degradação, sendo necessária a adição de hidróxido de sódio para um aumento destes percentuais. ${ }^{42}$ Acetona e acetonitrila são miscíveis com água e promovem a extração em uma fase única quando em contato com a matriz. Quando uma extração é realizada com acetona há necessidade de adição de solventes apolares para que ocorra a separação entre as fases orgânica e aquosa, o mesmo não é necessário quando se utiliza acetonitrila, uma vez que a adição de sais ao extrato faz com que ocorra tal separação. ${ }^{41}$

As desvantagens da utilização de acetonitrila como solvente de extração, quando comparada com acetona e acetato de etila incluem: grande volume de expansão durante vaporização no cromatógrafo a gás; interferências nos detectores termoiônico específico de chama e de condutividade eletrolítica, além de apresentar considerável toxicidade. ${ }^{41} \mathrm{~A}$ utilização de acetonitrila, entretanto, possibilita a extração de uma menor quantidade de coextrativos lipofílicos provenientes da amostra, como por exemplo, ceras, gorduras e pigmentos, e proporciona a extração de uma ampla faixa de pesticidas com diferentes polaridades. ${ }^{43}$ Acetonitrila quando acidificada permite recuperações satisfatórias de pesticidas que geralmente apresentam problemas de estabilidade. Uma outra grande vantagem é que acetonitrila é mais adequada para cromatografia líquida (Liquid Chromatography, LC) acoplada à espectrometria de massas (Mass Spectrometry, MS) do que acetona e acetato de etila. ${ }^{41}$ Sendo assim, acetonitrila foi escolhida como solvente de extração para o método QuEChERS, empregando-se $10 \mathrm{~mL}$ do solvente para $10 \mathrm{~g}$ de amostra, resultando uma relação $1 \mathrm{~g}$ de amostra por $1 \mathrm{~mL}$ de solvente, sem envolver etapa de evaporação. Este valor é considerado baixo se comparado a outros métodos de extração que normalmente apresentam uma relação entre amostra e solvente de 2 a $5 \mathrm{~g}$ por $1 \mathrm{~mL}$ no extrato final. Porém, com a instrumentação analítica disponível atualmente, esta relação é considerada adequada uma vez que valores de LD entre $10 \mathrm{e} 100 \mu \mathrm{g} \mathrm{kg}^{-1}$ são obtidos para a maioria dos pesticidas comumente analisados. ${ }^{5}$

\section{Diferentes formas de agitação}

A maioria dos métodos multirresíduo de preparo de amostra empregam blenders, como o Ultraturrax, durante o procedimento de extração. Em 1999, Cock et al. desenvolveram um dos primeiros procedimentos de extração multirresíduo de 89 pesticidas em espinafre, laranja, tomate e pêssego, fornecendo resultados bastante satisfatórios comparáveis aos do método mini-Luke, que utiliza Ultraturrax. ${ }^{44} \mathrm{O}$ procedimento de agitação manual ou com auxílio do Vortex possui várias vantagens em relação à agitação mecânica, tais como, possibilidade de realizar a extração a campo; a extração ocorre em um único frasco fechado não expondo o analista; rapidez, uma vez que não há necessidade de lavagem do homogeneizador entre extrações. Portanto, no desenvolvimento do método QuEChERS foi escolhida agitação utilizando Vortex. ${ }^{5}$

\section{Adição de sais e a separação de fases}

A adição de sais para promover o efeito salting ou" tem sido utilizada em vários métodos multirresíduo. Dependendo da natureza do solvente utilizado na etapa de partição obtém-se melhores percentuais de recuperação para analitos polares, uma vez que a adição de sais diminui a solubilidade destes compostos na fase aquosa, bem como a quantidade de água na fase orgânica e vice-versa. ${ }^{45}$

Nos métodos multirresíduo que utilizam acetona, a partição é controlada através de uma combinação de $\mathrm{NaCl}$ e solventes apolares, porém tem como desvantagens a diluição do extrato e o consumo de um maior volume de solvente. ${ }^{46,47}$ Entretanto, os métodos multirresíduo que utilizam acetonitrila, desenvolvidos até então, não empregam adição de nenhum tipo de solvente apolar no processo de partição. Na extração com acetonitrila, a adição de sais é muito conveniente uma vez que é rápida, fácil, apresenta baixo custo, tem a grande vantagem de não diluir o extrato da amostra e proporciona a separação das fases orgânica e aquosa. ${ }^{48,49}$

A utilização de sais secantes para melhorar a recuperação de pesticidas polares foi descrita por Andersson et al. ${ }^{50}$ os quais utilizaram sulfato de sódio $\left(\mathrm{Na}_{2} \mathrm{SO}_{4}\right)$. No desenvolvimento do método QuEChERS foi empregada uma mistura de $1 \mathrm{~g}$ de $\mathrm{NaCl}$ e $4 \mathrm{~g}$ de sulfato de magnésio $\left(\mathrm{MgSO}_{4}\right)$. A escolha do $\mathrm{MgSO}_{4}$ foi devido a maior capacidade de remover água quando comparado a outros sais. Além de reduzir o volume de fase aquosa, sua hidratação é uma reação exotérmica, tendo como resultado o aquecimento entre 40 e 45 ${ }^{\circ} \mathrm{C}$ da amostra durante as etapas de extração/partição, favorecendo a extração, especialmente dos compostos apolares. ${ }^{5}$

\section{Clean-up}

A etapa de clean-up é essencial para promover robustez e confiabilidade aos resultados obtidos pelo sistema cromatográfico, uma vez que componentes não-voláteis da matriz podem ficar aderidos no conjunto injetor-insersor e também na coluna cromatográfica, alterando a resposta do sistema e aumentando a frequência de manutenções necessárias. ${ }^{51,52}$

Tradicionalmente as etapas de clean-up empregam SPE, a qual utiliza cartuchos ou colunas que contêm entre 250 e 1000 mg de sorvente. Esta técnica envolve operação manual, uso de diferentes solventes para lavagem do sorvente, etapas de evaporação e secagem. Muitos fatores afetam a precisão quando se trabalha com SPE, entre eles o ajuste do sistema de vácuo e o fluxo dos solventes. Esta técnica quando automatizada requer manutenção frequente, além dos sistemas hoje disponíveis apresentarem um custo considerável..$^{53,54}$

Um novo método de clean-up denominado extração em fase sólida dispersiva (Dispersive Solid Phase Extraction, D-SPE) foi proposto 
juntamente com o método QuEChERS, ${ }^{5}$ onde $1 \mathrm{~mL}$ do extrato é colocado em contato com uma mistura contendo $25 \mathrm{mg}$ do sorvente amina primária-secundária (primary secondary amine, PSA) e 150 $\mathrm{mg}$ de $\mathrm{MgSO}_{4}$. Ao contrário dos métodos já existentes para clean-up com SPE que utilizam cartuchos ou colunas, a D-SPE permite que o clean-up e a redução de água residual sejam efetuados de uma forma rápida e simultânea. Esta etapa de remoção de água proporciona um extrato final de menor polaridade, facilitando assim a precipitação de coextrativos polares. O sorvente retém as interferências da matriz, sendo que depois da agitação manual e centrifugação o extrato está pronto para ser injetado no sistema cromatográfico. ${ }^{2,55,56} \mathrm{~A}$ estrutura bidentada do PSA tem um elevado efeito quelante, devido à presença dos grupos amino primário e secundário. Como resultado, a retenção de ácidos graxos livres e de outros compostos polares presentes na matriz é muito forte. Um clean-up eficiente garante uma maior vida útil para os insersores, bem como para as colunas cromatográficas, reduzindo assim a contaminação do sistema cromatográfico. ${ }^{57}$

\section{Utilização de padrão interno x minimização de erros}

Um dos principais objetivos dos métodos multirresíduo é o aumento da eficiência no laboratório e a redução das fontes de erros, minimizando a incerteza do resultado final. A propagação dos erros nas etapas do método QuEChERS foi monitorada através da utilização do padrão interno trifenilfostato, que apresenta as vantagens de fornecer altos percentuais de recuperação $(>98 \%)$ na fase orgânica, não interagir com o sorvente PSA utilizado na etapa de clean-up, além de ser um excelente padrão interno para LC e GC. ${ }^{5}$

\section{Efeito matriz e protetores dos analitos}

Os analitos injetados no sistema cromatográfico interagem com a fase estacionária da coluna cromatográfica e com outras superfícies como, por exemplo, o injetor do cromatógrafo a gás. No injetor, onde estão localizados o insersor e a parte inicial da coluna, há uma forte atividade, uma vez que estas partes se tornam recobertas por um filme de componentes não-voláteis com fortes interações. Estas interações são responsáveis pelos picos com cauda e pela degradação de algumas classes de pesticidas. Estes efeitos podem ser reduzidos quando se utilizam na solução de injeção os componentes da matriz provenientes do extrato. Estes promovem uma melhor transferência dos analitos para a coluna, quando comparada com a injeção dos analitos em solvente puro, comportamento conhecido por efeito matriz. ${ }^{58}$ Vários são os fatores que envolvem o efeito matriz, entre eles podemos citar: número e tipo de sítios ativos localizados no injetor e na coluna, estrutura química dos analitos, concentração dos analitos, temperatura de injeção, tempo de interação, além do tipo e da concentração da matriz. ${ }^{5}$ Sendo assim, muitos laboratórios preparam os padrões para GC no extrato "branco" da matriz com a finalidade de obter um melhor sinal cromatográfico e limites de detecção mais baixos. Porém este procedimento apresenta algumas desvantagens como, por exemplo, a dificuldade de obtenção de "brancos", além do aumento nas manutenções do sistema, uma vez que uma maior quantidade de matriz será injetada no sistema. Algumas agências como a Environmental Protection Agency (EPA) e a Food and Drug Administration (FDA) não permitem esta prática. $^{5}$

$\mathrm{Na}$ análise por LC-MS a presença da matriz pode resultar em mudanças na eficiência de ionização, uma vez que pode ocorrer supressão ou aumento da ionização. O mecanismo exato da supressão iônica é desconhecido, porém é causado pela presença de substâncias não-voláteis e por compostos com superfície bastante ativa. O efeito matriz também é dependente da natureza química do analito, pois a eficiência de ionização dos compostos polares é mais influenciada pela presença de coeluatos provenientes da matriz quando comparada com compostos apolares. Alguns parâmetros instrumentais, como fonte de ionização e vazão da fase móvel, também influenciam na extensão do efeito matriz. ${ }^{59}$

Anastassiades et al. observaram que a utilização de PSA como sorvente na etapa de clean-up removia a maior parte dos coextrativos presentes no extrato, havendo a possibilidade de degradação de alguns analitos no momento da injeção. ${ }^{5}$ Sendo assim, baseados nos estudos de Erney et al. ${ }^{58}$ estudaram diferentes compostos que poderiam ser utilizados no lugar do extrato "branco" da matriz; estes foram denominados de "protetores" dos analitos. ${ }^{60}$ Neste estudo foram avaliadas mais de 90 substâncias de diferentes classes químicas; as que apresentaram os melhores resultados foram etilglicerol, gulonalactona e sorbitol. O uso destes compostos nas soluções a serem injetadas no sistema cromatográfico impede que os analitos de interesse sofram degradação e/ou adsorção no mesmo. Além disso, outras grandes vantagens são a facilidade no preparo das soluções padrão contendo estas substâncias e uma menor frequência de manutenções no sistema cromatográfico. ${ }^{60,61}$

\section{MODIFICAÇÕES DO MÉTODO QuEChERS}

\section{Efeito do pH}

Pesticidas tais como tiabendazol, imazalil, carbendazina, captana, folpete, diclofluanida, clorotalonil, entre outros, são sensíveis ao $\mathrm{pH}$ do meio e requerem condições analíticas adequadas para evitar perdas ${ }^{38}$ Em geral, os pesticidas são estáveis em $\mathrm{pH}$ ácido, porém alguns compostos, por exemplo, imazalil e tiabendazol, apresentam baixos percentuais de recuperação quando em $\mathrm{pH}$ ácido, devido ao fato de estarem protonados e solubilizados na fase aquosa, não sendo recuperados na etapa de partição. As frutas e os vegetais apresentam um pH natural que varia entre 2,5 e 6,5. Portanto, o ajuste do $\mathrm{pH}$ também está relacionado à presença de coextrativos na fase orgânica, uma vez que se observa uma maior presença de gordura e ácidos graxos quando a extração é efetuada em meio ácido. No método QuEChERS original não foi realizada nenhuma correção de $\mathrm{pH}$, porém os autores obtiveram resultados bastante variáveis para os pesticidas captana, clorotalonil, diclofluanida, dicofol, folpet, pimetrozina e tolilfluanida., ${ }^{5,62}$

Estes compostos são conhecidos devido à dificuldade de quantificação, sendo que nos métodos multirresíduo atuais são geralmente analisados no modo screening e, posteriormente, utilizam-se técnicas mais específicas para se obter resultados adequados. ${ }^{62,63}$ Observa-se que folpete, captana, diclofluanida e tolilfluanida possuem em suas estruturas o grupo funcional $\mathrm{N}$-trialometil, principal fonte de instabilidade destas estruturas. Em pH alcalino, sob determinadas condições, captana e captafol degradam a tetra-hidroftalamida, folpete sofre conversão à ftalamida, e diclofluanida e tolilfluanida degradam a N',N"-dimetil-Nfenilsulfamida e dimetilamino-sulfotoluidina, respectivamente. Além destes, dicofol e clorotalonil convertem-se em diclorobenzofenona e 4-hidroxi-2,5,6-tricloroisoftalonitrila, respectivamente. Estes produtos de degradação atestam a presença dos pesticidas que lhes deram origem. Nos casos em que grandes quantidades de metabólitos são encontrados, é normal que se realize uma análise mais específica utilizando outros métodos de preparo e/ou análise. ${ }^{64-66}$

As causas dos problemas encontrados na análise destes compostos são diversas e difíceis de serem controladas. Como exemplo destes parâmetros que influenciam a taxa de degradação pode-se citar $\mathrm{pH}$, tipo de solvente, luminosidade, componentes da matriz, temperatura, teor de água e concentração do analito. Estes pesticidas também são suscetíveis a efeitos adversos provenientes do sistema de injeção e da coluna. A fonte do espectrômetro de massas também está sujeita a estes problemas, uma vez que o espectro de massas destes compostos obtido no modo de ionização por impacto de elétrons, geralmente, não exibe o íon molecular. 
Como exemplo podem-se citar as dificuldades encontradas na análise de captana devido a este se dissociar em íons de razão massa/carga $(\mathrm{m} / \mathrm{z}$ ) baixa. Portanto, quando resultados não satisfatórios são obtidos para estes compostos é difícil indicar a causa de sua degradação, uma vez que pode ser proveniente do processamento da amostra, extração, clean-up, dos sistemas de injeção, separação e/ou detecção. ${ }^{66}$

Mastvoska e Lehotay estabeleceram que a adição de $0,1 \%$ (v/v) de ácido acético (HAc) em acetonitrila aumenta a estabilidade de pesticidas antes da análise. ${ }^{41}$ Entretanto, não observaram aumento significativo dos percentuais de recuperação obtidos através da extração de uma mistura de matrizes de pêssego, ameixa, pepino e pimenta verde fortificada ao nível de $500 \mu \mathrm{g} \mathrm{kg}^{-1}$ utilizando método QuEChERS original sem adição de ácido acético e com adição de 0,1; 0,5 e 1,0\% (v/v) de ácido acético em acetonitrila. Surpreendentemente, o aumento da concentração de ácido acético não foi acompanhado por um aumento significativo das recuperações. Os resultados demonstraram que com a adição de ácido acético menores percentuais de recuperação $(<30 \%)$ foram obtidos para clorotalonil e diclofluanida, sendo este último o fungicida com grupo N-trialometil mais sensível à degradação na presença de acetonitrila. Sendo assim, a adição de ácido acético na acetonitrila, seguida da utilização de $\mathrm{NaCl}+\mathrm{MgSO}_{4}$ para promover o processo de partição, não trouxe uma melhora significativa. ${ }^{62}$

$\mathrm{O}$ pH é importante tanto para compostos sensíveis à degradação em meio alcalino, como para aqueles sensíveis em meio ácido como, por exemplo, pimetrozina. Assim, recomenda-se uma faixa de $\mathrm{pH}$ entre 4 e 5 , uma vez que a mesma proporciona boas recuperações $(>70 \%)$ para pesticidas sensíveis em meio ácido, além de garantir estabilidade para aqueles pesticidas sensíveis em meio alcalino. $\mathrm{O}$ tamponamento dos extratos entre $\mathrm{pH} 4$ e 5 com ácido acético $(\mathrm{pKa}=4,75)$ e acetato de sódio $(\mathrm{NaAc})$ tem sido adotado. Ácido acético e acetato de sódio estão presentes de forma natural em várias frutas e vegetais, portanto, a utilização deste tampão evita que novos reagentes sejam utilizados e que interferências indesejáveis venham a ocorrer. ${ }^{62}$

Para não aumentar o número de etapas do método original, ${ }^{5} \mathrm{a}$ adição dos reagentes que formam o tampão foi efetuada da seguinte forma: o ácido acético $(1 \% \mathrm{v} / \mathrm{v})$ foi adicionado à acetonitrila e o acetato de sódio $(1,5 \mathrm{~g})$ foi adicionado no lugar de cloreto de sódio. É importante salientar que durante a modificação, ilustrada na Figura 2, a agitação por Vortex foi substituída por agitação manual. Além disso, outro fator relevante a ser considerado é a maior quantidade de amostra $(15 \mathrm{~g})$ e de solvente $(15 \mathrm{~mL})$ utilizados no método modificado. A fim de aumentar a quantidade de extrato disponível para a realização da etapa de clean-up, faz-se a posterior evaporação e reconstituição do extrato em tolueno. Este procedimento opcional tem como objetivo possibilitar a análise do extrato em detectores clássicos utilizados em cromatografia gasosa. ${ }^{62}$

\section{Etapa de clean-up}

No método QuEChERS original, a etapa de clean-up dispersivo utilizando o sorvente PSA é muito eficiente na remoção de ácidos graxos e outros ácidos orgânicos presentes nos alimentos, entretanto, ineficiente na remoção de clorofila e esteróis de extratos vegetais. A clorofila não interfere diretamente na análise cromatográfica de pesticidas, porém fica retida no insersor do injetor aumentando a necessidade de troca deste e das manutenções na coluna cromatográfica. ${ }^{62}$

A utilização de cartuchos contendo PSA e carbono grafitizado foi reportada por Lehotay et al. para a remoção de clorofila e esteróis provenientes de amostras de alface, porém o carbono grafitizado (Grafitized Carbon Black, GCB) tem como característica a forte retenção de pesticidas que apresentam estruturas planares, como tiabendazol, hexaclobenzeno e terbufós, entre outros. Este problema foi minimizado através do uso de tolueno na eluição. O uso de GCB

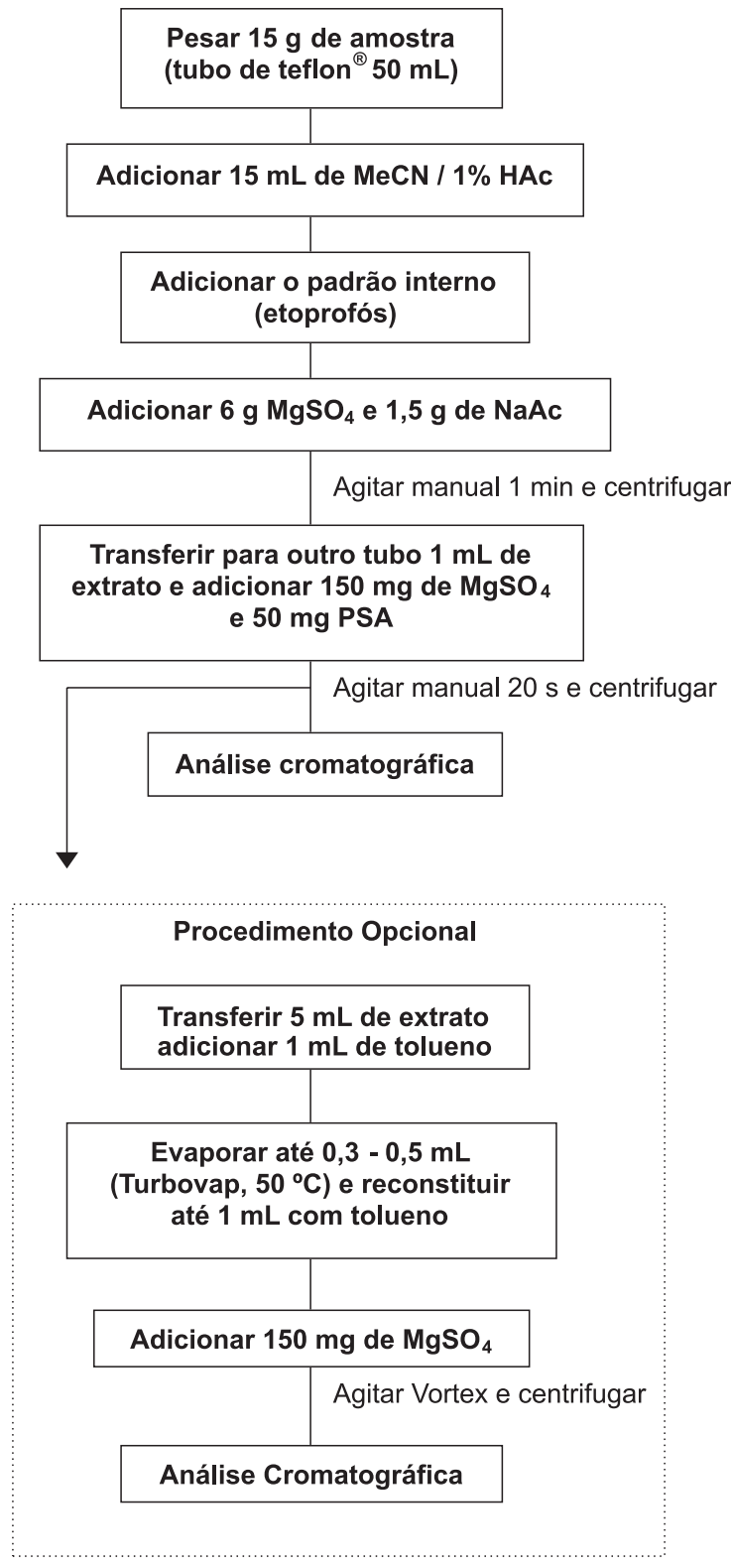

Figura 2. Fluxograma representativo do método QuEChERS modificado

proporcionou uma remoção adicional de extrativos quando comparado com PSA na etapa de clean-up. ${ }^{62}$

Lehotay et al. avaliaram a modificação do método QuEChERS para extração de 32 pesticidas utilizando uma mistura de $\mathrm{C}_{18}$ e PSA na etapa de clean-up de amostras contendo um alto teor de gordura como, por exemplo, leite, ovo e abacate. ${ }^{67}$ A combinação de $\mathrm{C}_{18} \mathrm{e}$ PSA proporcionou bons resultados na etapa de D-SPE, apresentando recuperações na faixa de 70-120\% com valores de RSD $\leq 10 \%$ para a maioria dos compostos avaliados. A utilização de $\mathrm{C}_{18}$ na etapa de clean-up do método QuEChERS tem sido demonstrada para amostras contendo teores de gordura $\geq 2 \%$ como, por exemplo, arroz, cevada, trigo, óleos vegetais entre outras. ${ }^{68-71}$

\section{TÉCNICAS CROMATOGRÁFICAS ACOPLADAS À ESPECTROMETRIA DE MASSAS}

Desde os anos 1970 têm-se utilizado a técnica de GC acoplada a sistemas clássicos de detecção como, por exemplo, detecção por captura de elétrons (Electron Capture Detection, ECD), detecção de 
nitrogênio e fósforo (Nitrogen and Phosphorus Detection, NPD) e detecção por fotometria de chama (Flame Photometric Detection, FPD) para a determinação de resíduos de pesticidas. ${ }^{72,73}$ Porém, muitos pesticidas que eram analisados por estes detectores, estão sendo substituídos por outros compostos que possuem, em geral, melhor ação e menor impacto ambiental, entretanto muitos quando analisados por GC, não são detectados ao nível de $\mu \mathrm{g} \mathrm{kg}^{-1}$. $^{74}$

Atualmente, a técnica GC-MS é utilizada com frequência para determinação multirresíduo de pesticidas em alimentos. A facilidade do acoplamento GC-MS, além da disponibilidade de um banco de espectros de massas padrão obtidos no modo de ionização por impacto de elétrons (Electron Ionization, EI) ajudaram na disseminação da técnica GC-MS. ${ }^{75,76}$

GC-MS é uma das principais ferramentas aplicadas em análise de resíduos de pesticidas por permitir que a confirmação e a determinação de um grande número de compostos seja feita simultaneamente. Os baixos LD's obtidos são consequência da alta seletividade promovida pelo uso de diferentes modos como, por exemplo, o modo SIM que tem sido utilizado para determinar resíduos de pesticidas em alimentos. ${ }^{77,78}$

A ionização dos pesticidas em GC-MS pode ser realizada utilizando os modos EI e ionização química (Chemical Ionization, CI), positiva ou negativa. As vantagens da utilização do modo EI são a baixa influência da estrutura molecular na resposta e o grande número de fragmentos característicos que são gerados. Entretanto, o modo CI positivo ou negativo proporciona uma melhor seletividade para muitos pesticidas quando comparado com o modo EI. O modo CI é preferencialmente utilizado para a determinação de organo-halogenados, piretróides e organofosforados. Este modo é menos utilizado em métodos multirresíduo, por não ser uma técnica de ionização universal, além de fornecer espectros contendo um pequeno número de fragmentos, oferecendo menos informação qualitativa. ${ }^{74}$

Na seletividade, porém, interferências provenientes da matriz podem influenciar o resultado, e a identificação dos analitos pode ficar comprometida. Recentes avanços em MS propõem um aumento da especificidade, a partir da exclusão dos íons dos interferentes da amostra. Uma maior seletividade também é observada quando se utiliza CI, entretanto, a informação relacionada à estrutura dos compostos que estão sendo analisados também é diminuída. ${ }^{79}$

Os íons que são formados, tanto por EI como por CI precisam ser separados de acordo com suas razões $m / z$. Há 4 classes de analisadores (filtros de massas), que são utilizados para selecionar e filtrar os íons, sendo eles: rádio frequência (tanto quadrupolo quanto trapeamento de íons); ${ }^{80}$ tempo de vôo; transformada de Fourier e setor magnético, sendo que os mais utilizados são a rádio frequência e o tempo de vôo. ${ }^{13}$

$\mathrm{O}$ uso de GC acoplada à espectrometria de massas sequencial (Tandem Mass Spectrometry, MS/MS) promove um aumento de seletividade em conjunto com uma redução do ruído, sem perder a capacidade de identificação, permitindo a análise de resíduos de pesticidas ao nível de traços na presença de interferentes provenientes da matriz. Esta técnica é particularmente utilizada na análise de amostras complexas, uma vez que permite a determinação de diferentes analitos coeluentes. ${ }^{81}$ Nos últimos anos, vários avanços na área de instrumentação possibilitaram aos equipamentos um aumento de sensibilidade, sendo possível a identificação e quantificação de analitos em níveis inferiores aos estabelecidos pelos Limites Máximos de Resíduos (LMR's). Entre estes avanços podemos citar os sistemas de injeção de grandes volumes (Large Volume Injection - LVI), que permitem a injeção de uma maior quantidade de extrato e consequentemente de analitos, promovendo um aumento significativo de sensibilidade. Outro avanço bastante significativo nos sistemas de injeção foi a possibilidade da realiza- ção de programação de temperatura de vaporização (Programmed Temperature Vaporized - PTV) que possibilita a obtenção de uma melhor resposta cromatográfica. ${ }^{77}$

O grande desafio para os analistas no desenvolvimento de um método multirresíduo é a obtenção de percentuais satisfatórios de recuperação dos analitos, bem como a minimização das interferências através da utilização de métodos de extração e clean-up apropriados. ${ }^{32}$ Nos últimos anos, várias foram as aplicações e modificações realizadas no método QuEChERS, afim de alcançar este objetivo. Na Tabela 1 é realizada uma descrição da utilização deste método na determinação de resíduos de pesticidas em alimentos por GC-MS/MS.

No passado, os métodos que utilizavam LC eram aplicados com menor frequência na análise de resíduos de pesticidas, devido a uma menor seletividade e sensibilidade apresentada pelos detectores utilizados como, por exemplo, ultravioleta e arranjo de diodos quando comparados com os métodos de GC existentes na época. ${ }^{74}$ Porém, o desenvolvimento de pesticidas polares, que apresentam em geral menor persistência e toxicidade quando comparados com os compostos apolares, exigiu a adequação dos métodos de análise existentes, uma vez que a maioria destes novos compostos não apresenta uma boa resposta quando analisados por GC. ${ }^{102} \mathrm{~A}$ potencialidade do acoplamento entre LC e MS já havia sido reconhecida há várias décadas, porém incompatibilidades relacionadas à vazão do eluente com relação à velocidade de bombeamento do sistema de vácuo e o projeto da fonte de íons do espectrômetro de massas fez com que a utilização desta técnica em análises de rotina ocorresse recentemente. ${ }^{76}$ Este acoplamento oferece uma série de vantagens, dentre elas, elevada sensibilidade e seletividade. ${ }^{74}$

Desde o desenvolvimento de fontes de ionização que operam à pressão atmosférica (Atmospheric Pressure Ionization, API) como, por exemplo, a ionização por eletronebulização (Electrospray Ionization, ESI) e a ionização química à pressão atmosférica (Atmospheric Pressure Chemical Ionization, APCI), vários instrumentos robustos e confiáveis estão disponíveis. Assim como ocorre com GC-MS/MS, a LC-MS/MS permite um aumento de seletividade e sensibilidade proporcionando o monitoramento de centenas de pesticidas em uma única análise. ${ }^{74,76}$ LC-MS/MS tornou-se uma ferramenta indispensável em laboratórios que trabalham com análise multirresíduo de pesticidas. Apesar do alto custo de aquisição e manutenção destes equipamentos, apresentam uma série de vantagens, entre elas alta eficiência analítica, menor tempo no desenvolvimento de métodos e elevada robustez. ${ }^{55}$ Nos últimos anos, vários estudos e determinações de resíduos de pesticidas, utilizando o método QuEChERS e LC-MS/ MS, têm sido realizados em diversos tipos de alimentos, conforme descrito na Tabela 2.

\section{VERSATILIDADE E FUTURO DO MÉTODO QUEChERS}

As modificações já realizadas neste método indicam um futuro promissor na análise multirresíduo de pesticidas em alimentos e outros produtos agrícolas. Além dos trabalhos citados nesta revisão, o método tem sido aplicado com sucesso para a extração de pesticidas em outras matrizes. Lee et al. utilizaram o método QuEChERS para extração de 49 pesticidas multiclasse em folhas de fumo. Na determinação destes compostos empregou-se GC-MS/MS. Os valores de recuperação ficaram na faixa de 71,9 a 120,1\%, com valores de RSD $\leq 13,9 \%$ e valores de Limite de Quantificação (Limit of Quantification - LQ) na faixa de 0,015 a 0,157 $\mathrm{mg} \mathrm{kg}^{-1} \cdot{ }^{109}$ As técnicas de GC-MS e LC-MS/MS foram utilizadas na determinação de 24 pesticidas em amostras de solo, que foram extraídas utilizando o método QuEChERS. Os compostos analisados apresentaram recuperação média de $72,7 \%$, com RSD na faixa de 1,5 a $18,3 \%$. As faixas de LD e LQ ficaram entre 0,02 e $88 \mu \mathrm{g}$ $\mathrm{kg}^{-1}$ e entre 0,08 e $292,0 \mu \mathrm{g} \mathrm{kg}^{-1}$, respectivamente. ${ }^{110}$ 


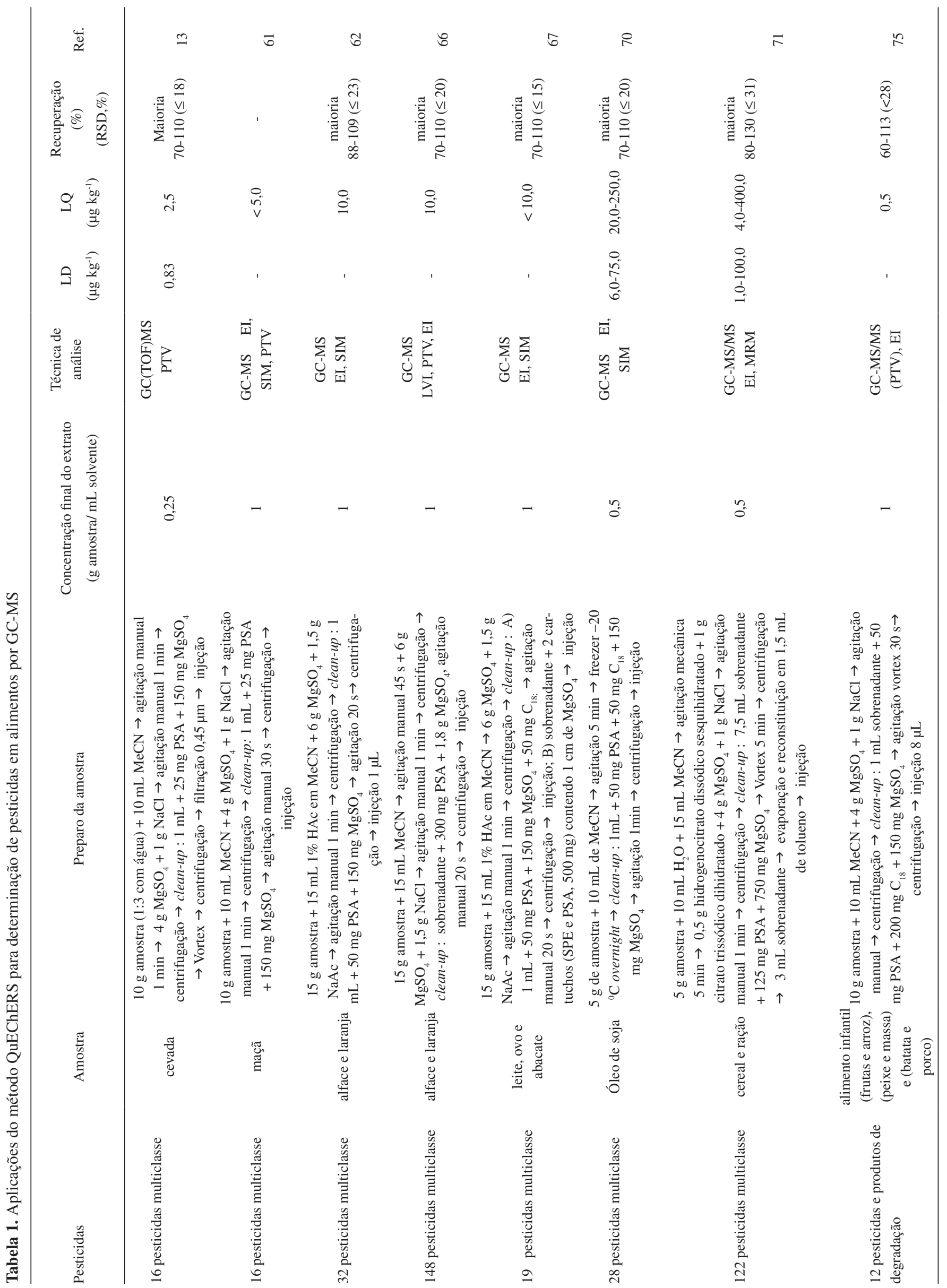




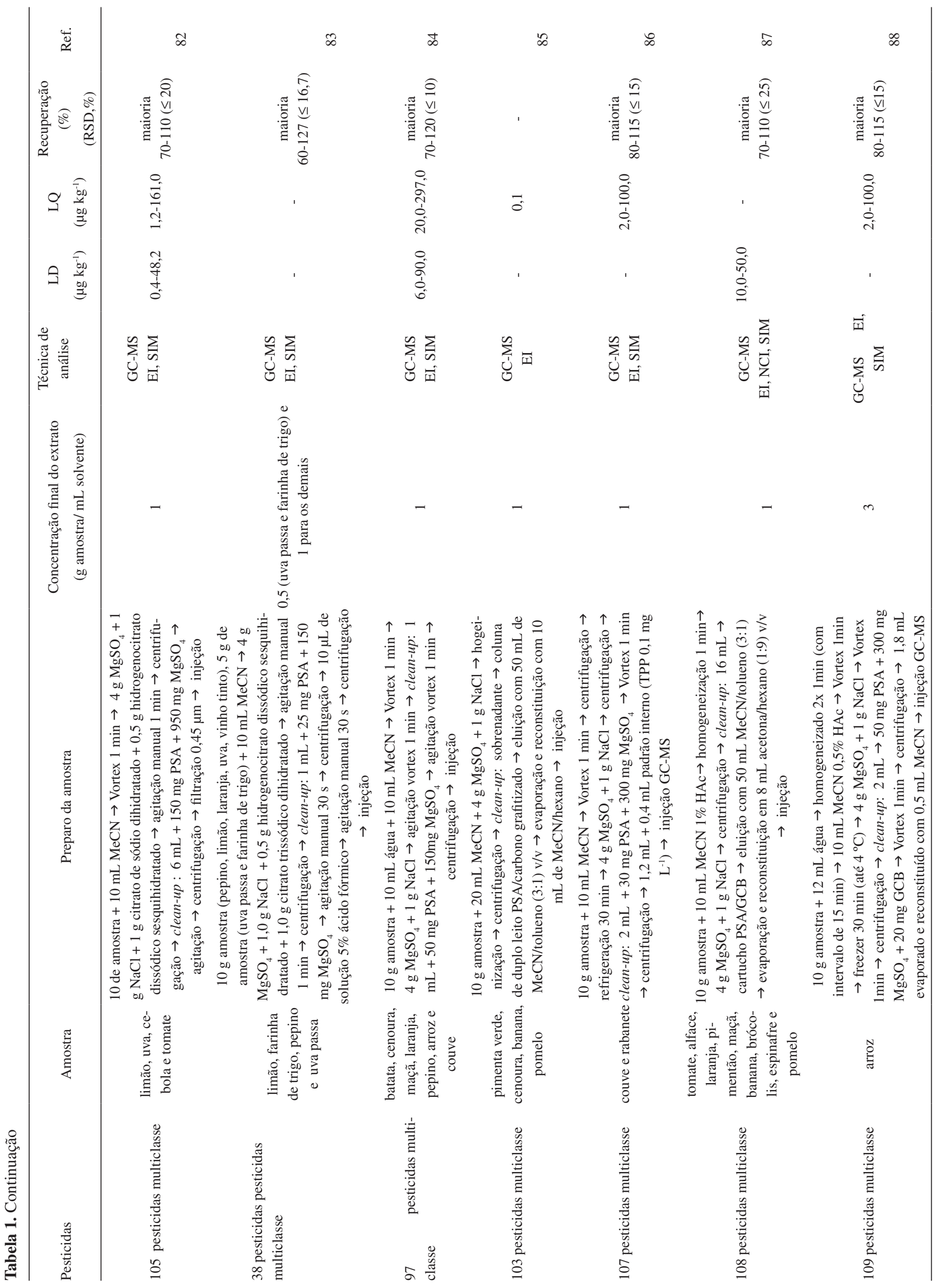




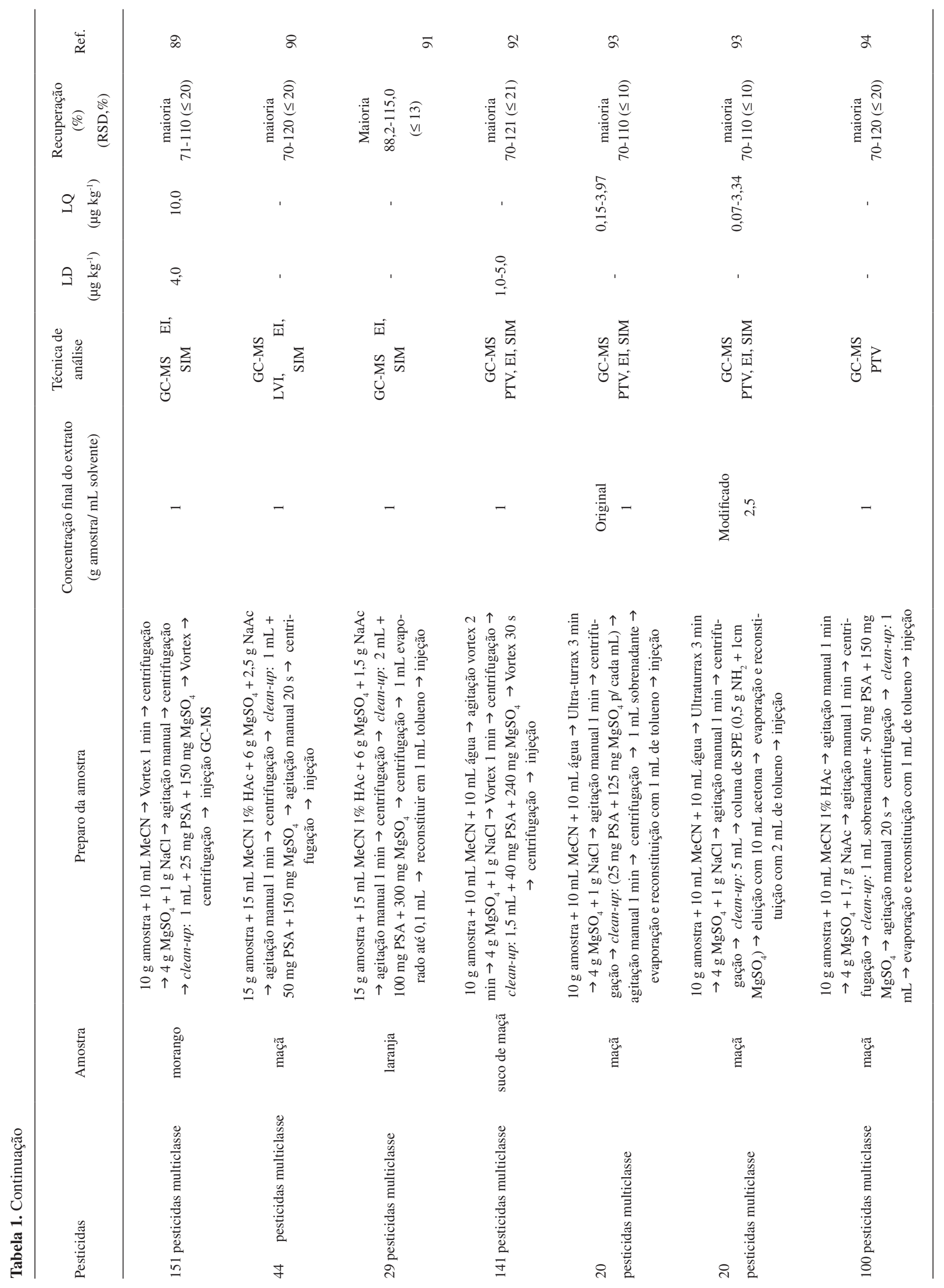




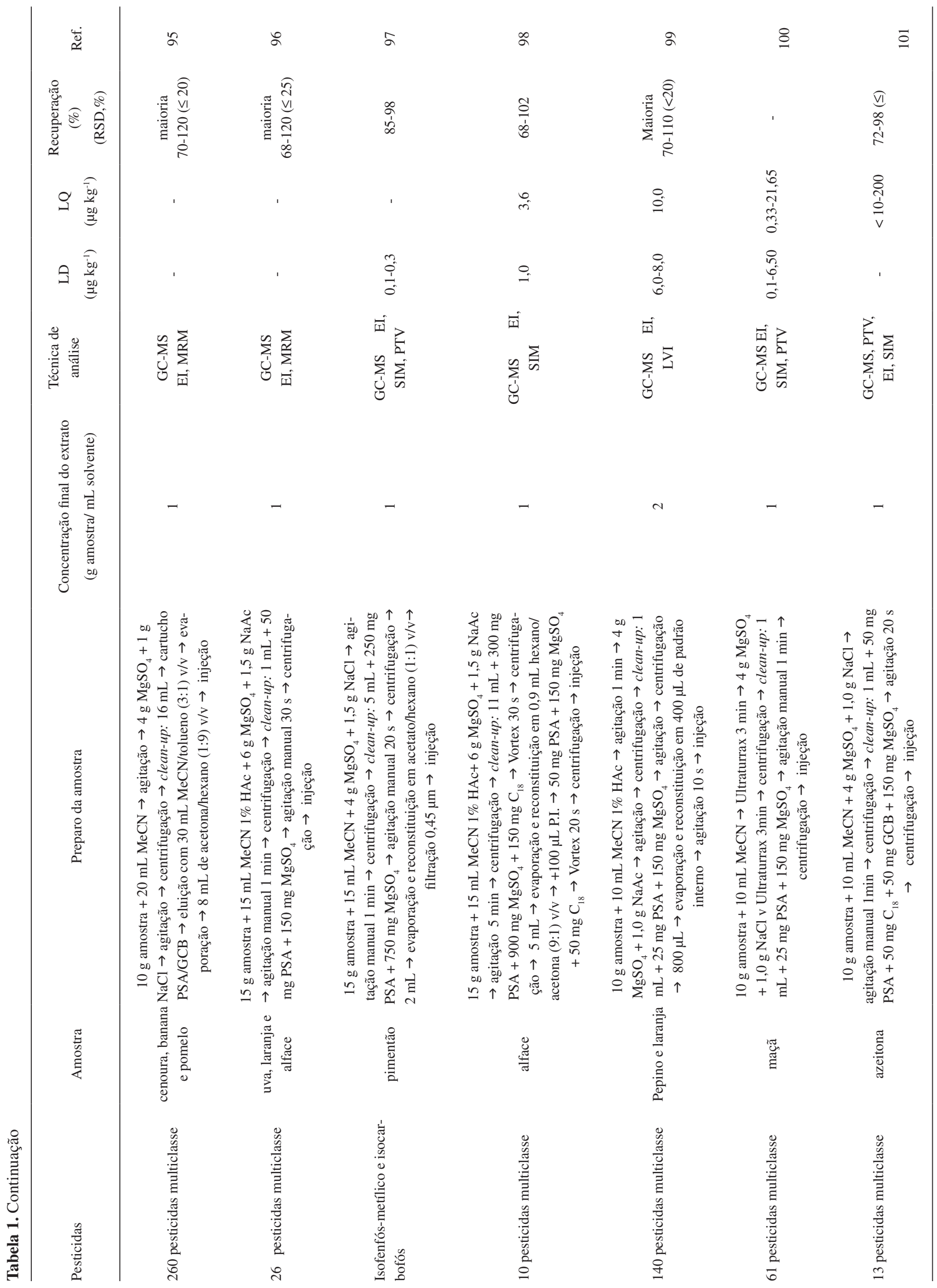




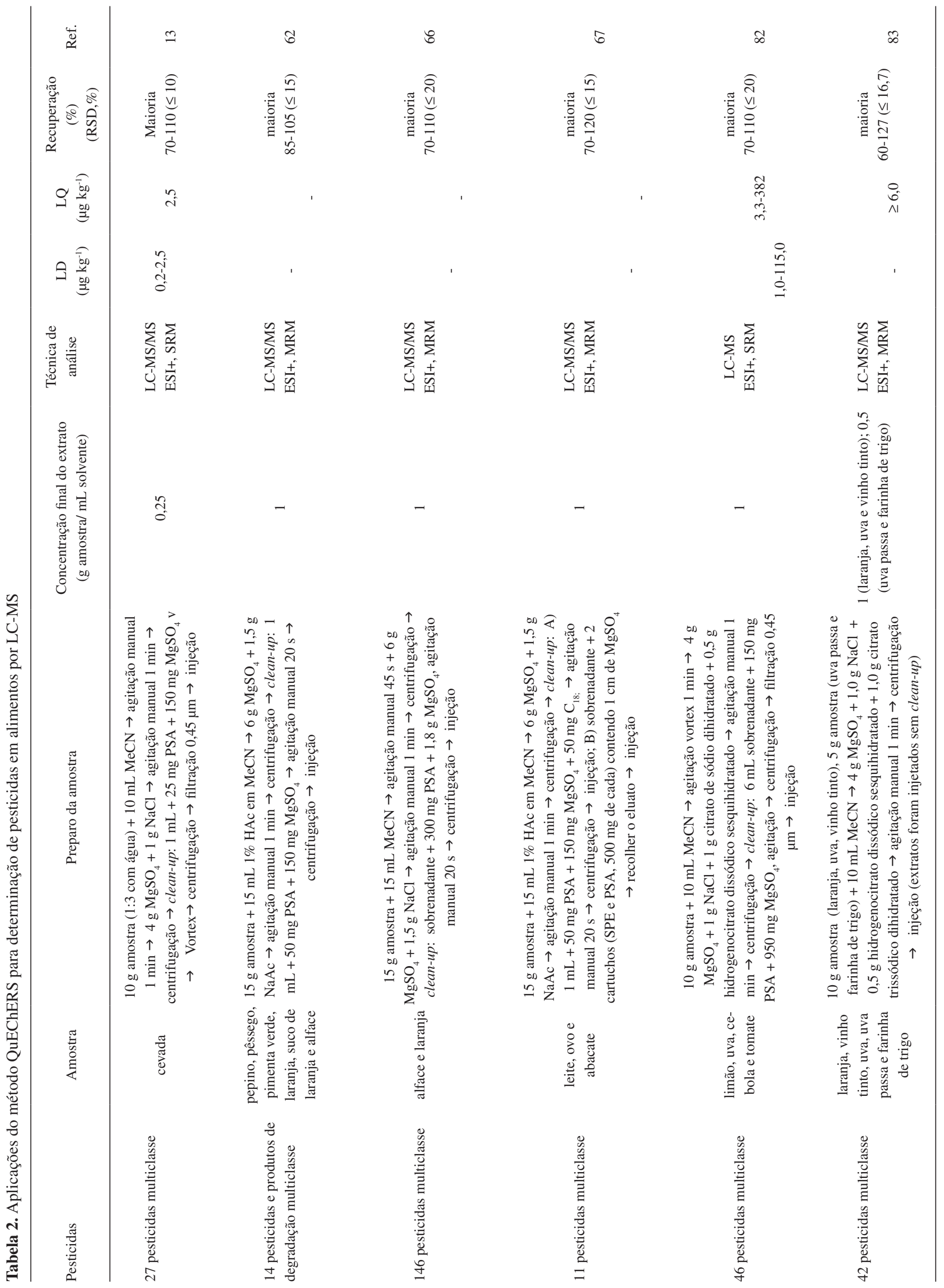




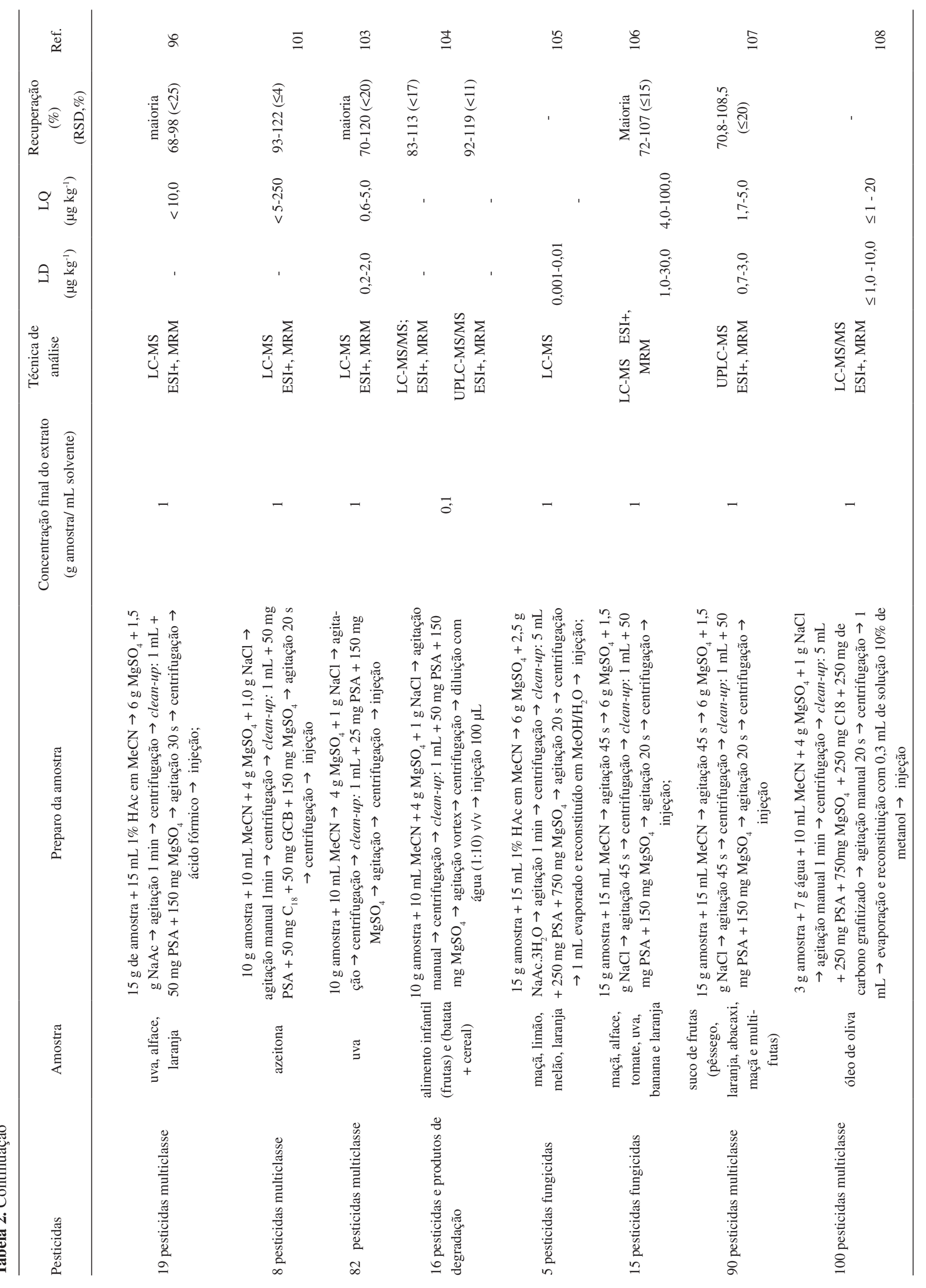


O método QuEChERS e a GC-MS foram empregados com sucesso na extração e determinação de 41 pesticidas (organoclorados e organofosforados) em uma mistura de plantas fitoterápicas (Scutellaria baicalensis e Acacia catechu). Os percentuais de recuperação obtidos ficaram entre 80 e $120 \%$, com RSD médio de $5,4 \%$ e valores de LD entre 20 e $180 \mu \mathrm{g} \mathrm{kg}^{-1}$ e LQ entre 24 e $235 \mu \mathrm{g} \mathrm{kg}{ }^{-1}$. 11

O método QuEChERS tem sido empregado de forma satisfatória quando aliado à espectrometria de massas, porém não está limitado somente a este tipo de detector. Hernández-Borges et al. utilizaram o método QuEChERS e GC-NPD para a determinação de 11 pesticidas em banana, com valores de LQ na faixa de 0,01 a $0,14 \mathrm{mg} \mathrm{kg}^{-1}$, percentuais de recuperação entre 67 e $118 \%$ e RSD $\leq 16 \% .{ }^{112} \mathrm{O}$ método QuEChERS foi utilizado na extração de 36 pesticidas em amostras de mel, seguida da determinação por GCECD e GC-NPD. Obtiveram-se percentuais de recuperação entre 70 e $120 \%$ e $\mathrm{RSD} \leq 22 \% .{ }^{113}$

Os inseticidas diflubenzurona e triflumurona foram extraídos de amostras de tomate empregando-se o método QuEChERS e determinados por LC acoplada a sistema de fotoderivatização pós-coluna com detector de quimioluminescência. A recuperação ficou entre 79,7 e 94,2\%, com valores de RSD $\leq 10 \%$, valores de $\mathrm{LD}$ na faixa de 0,05 a $0,26 \mu \mathrm{g} \mathrm{kg}^{-1}$ e valores de LQ entre 10 e $20 \mu \mathrm{g} \mathrm{kg}^{-1}$. ${ }^{114}$

Desde o seu desenvolvimento o método QuEChERS é utilizado na extração de resíduos de pesticidas. Além deste amplo campo de aplicação, este método tem sido usado na extração de outros tipos de analitos. Pan et al. utilizaram o método QuEChERS para a extração do antibiótico cloroanfenicol em amostras de mel, antes da quantificação empregando LC-MS. Obtiveram recuperações na faixa de 78 a $92 \%$, com RSD entre 4,8 e $8,9 \% .{ }^{115}$ GC-MS foi utilizado na determinação multirresíduo de 40 fármacos em amostras de sangue previamente extraídas aplicando-se o método QuEChERS. Os valores de recuperação ficaram na faixa de 56,0 a $103,7 \%$, com RSD $\leq 18,9 \% .{ }^{116}$ Fagerquist et al. aplicaram o método QuEChERS para extração de 10 antibióticos $\beta$-lactâmicos em rim de bovinos. Na determinação destes compostos utilizou-se LC-MS/ MS, obtendo-se recuperações na faixa de 56,4 a 80,9\%, com RSD entre 6,1 e 17,2\%. ${ }^{117}$ Mastovska e Lehotay determinaram satisfatoriamente resíduos de acrilamida, após extração com método QuEChERS, em cereais, manteiga de amendoim, chocolate, café e água empregando LC-MS/MS e GC-MS. ${ }^{118}$

LC-MS/MS e GC-MS foram empregadas na determinação multirresíduo de 221 pesticidas e 26 micotoxinas. Estes compostos foram extraídos de forma simultânea empregando método QuEChERS. Os percentuais de recuperação dos pesticidas analisados (52 compostos por GC-MS e 169 compostos por LC-MS/ MS) ficaram na faixa de 70 a $120 \%$, com valores de RSD $\leq 20 \%$. Para as 26 micotoxinas avaliadas por LC-MS/MS foram obtidos valores de LQ e LD entre 1 e $100 \mu \mathrm{g} \mathrm{kg}^{-1}$, e entre 0,4 e $0,8 \mu \mathrm{g}$ $\mathrm{kg}^{-1}$, respectivamente. Os percentuais de recuperação para $80 \%$ das micotoxinas avaliadas ficaram entre 70 e $120 \%$, com valores de $\mathrm{RSD} \leq 20 \%{ }^{68,119,120}$

Ensaios de proficiência empregando o método QuEChERS mostram que este método é robusto, sendo o método transferido com sucesso entre os laboratórios participantes. ${ }^{96}$ Nos Estados Unidos, este método foi adotado em 2007 como método oficial da Association of Official Analytical Chemists (AOAC) para a determinação de resíduos de pesticidas em alimentos. ${ }^{121} \mathrm{O}$ método QuEChERS também é considerado método oficial pelo European Committee for Standardization. ${ }^{122}$ Além disso, durante a $39^{\text {a }}$ sessão do Comitê de Resíduos de Pesticidas do Codex Alimentarius realizada em 2007, os Estados Unidos apresentaram a proposta de oficialização deste, como método padrão do Codex Alimentarius. ${ }^{123}$

\section{CONSIDERAÇÕES FINAIS}

O método QuEChERS possui muitas vantagens sobre os métodos tradicionais de preparo de amostra para determinação de resíduos de pesticidas, dentre elas podemos citar: altos percentuais de recuperação (> 85\%) são obtidos para um grande número de compostos de diferentes polaridade e volatilidade, incluindo pesticidas reconhecidos por sua dificuldade de análise como, por exemplo, metamidofós, ometoato, imazalil, tiabendazol, diclorvos, piretróides, entre outros; o método é exato e preciso, sendo estes itens assegurados pela utilização de padrão interno que permite que sejam feitas correções relacionadas aos diferentes teores de água presentes na amostra e, com isso, flutuações de volume em diferentes matrizes; permite o preparo de 10 a 20 amostras entre 30 e 40 min; utilização de um pequeno volume de solventes, além de não utilizar solventes clorados, a adição de acetonitrila quando realizada com dispensadores faz com que o analista tenha uma exposição mínima a este solvente; um único analista pode realizar o preparo da amostra; não requer a utilização de muitos materiais e equipamentos, bem como espaço físico durante a execução do método.

A principal desvantagem deste método está relacionada com a relação amostra/extrato final que é de $1 \mathrm{~g}$ por $1 \mathrm{~mL}$. Este valor é menor quando comparado com os obtidos com outros métodos que utilizam uma etapa de concentração apresentando relação amostra/extrato final de 2 a 5 g por $1 \mathrm{~mL} \cdot{ }^{18}$ Portanto, se a matriz não é uma fonte de ruídos nas análises isto pode conduzir, no método QuEChERS, a valores de LQ mais elevados, para o mesmo volume de injeção. Entretanto, considerando a alta sensibilidade das técnicas cromatográficas disponíveis atualmente, principalmente com GC-MS/MS e LC-MS/MS, o método QuEChERS é adequado e constitui o estado da arte para a determinação multirresíduo de pesticidas em diferentes alimentos.

\section{REFERÊNCIAS}

1. Pang, G. F.; Cao, Y.; Zhong, Zhang, J. J.; Fan, C. L.; Liu, Y. M.; Li, X. M.; Jia, G. Q.; Li, Z. Y.; Shi, Y. Q.; Wu, Y. P.; Guo, T. T.; J. Chromatogr. A 2006, 1125,1 .

2. Martinez-Vidal, J. L.; Arrebola-Liëbanas, F. J.; Gonzalez-Rodriguez, M. J.; Garrido-Frenich, A.; Fernández-Moreno, J. L.; Rapid Commun. Mass Spectrom. 2005, 20, 365.

3. Agência Nacional de Vigilância Sanitária (ANVISA), Rev. Saúde Pública 2006, 40, 361 .

4. Lehotay, S.; J. AOAC Int. 2002, 85, 1148.

5. Anastassiades, M.; Lehotay, S.; Stajnbaher, D.; Schenck, F. J.; J. AOAC Int. 2003, 83, 412 .

6. Hercegová, A.; Dömötörová, M.; Matisová, E.; J. Chromatogr., A 2007, 1153,54

7. Chen, Y.; Guo, Z.; Wang, X.; Qiu, C.; J. Chromatogr., A 2008, 1184, 191

8. Picó, Y.; Blasco, C.; Font, G.; Mass Spectrom. Rev. 2004, 23, 45.

9. Hajšlová, J.; Zrostlíková, J.; J. Chromatogr., A 2003, 1000, 181.

10. Hogenboo, M. A.; Zoonen, P.; J. Chromatogr., A 2000, 892, 435.

11. Luthje, K.; Hyotylainen, T.; Rautiainen-Rämä, M.; Riekkola, M. L.; Analyst 2005, 130, 52.

12. Mills, P. A.; Onley, J. J.; Gaither, R. A.; J. Assoc. Agric. Chem. 1963, 46, 186.

13. Diez, C.; Traag, W. A.; Zommer, P.; Marinero, P.; Atienza, J.; J. Chromatogr., A 2006, 1131, 11.

14. Schenck, F. J.; Callery, P.; Gannet, P. M.; Daft, J. R.; Lehotay, S. J.; J. AOAC Int. 2002, 85, 1177.

15. Mercer, G. E.; Hurlbut, J. A.; J. AOAC Int. 2004, 87, 1224.

16. Luke, M.; Froberg, J. E.; Masumoto H. T.; J. AOAC Int. 1975, 58, 1020 . 
17. Krijgsman, W.; Van De Kamp, C. G.; J. Chromatogr. 1976, 117, 201.

18. Hiemstra, M.; Kok, A.; J. Chromatogr., A 2007,1154, 3.

19. Garrido-Frenich, A.; Martínez-Salvador, I.; Martínez-Vidal, J. L.; LópezLópez, T.; Anal. Bioanal. Chem. 2005, 383, 1106.

20. Melo, L. F. C.; Collins, C. H.; Jardim, I. C. S. F.; J. Chromatogr., A 2005 $1073,75$.

21. Rodriguez, R.; Mañes, J.; Picó, Y.; Anal. Chem. 2003, 75, 452.

22. Lanças, F. M.;Extração em Fase Sólida (SPE), RiMa: São Carlos, 2004.

23. Picó, Y.; Fernández, M.; Ruiz, M. J.; Font, G.; J. Biochem. Biophys. Methods 2007, 70, 117.

24. Štajnbaher, D.; Zupančič-Kralj, L.; J. Chromatogr, A 2003, 1015, 185.

25. Barker, S. A.; Long, A. R.; Short, C. R.; J. Chromatogr., A 1989, 475, 353.

26. Arthur, C. L.; Pawliszyn, J.; Anal. Chem. 1990, 62, 2145.

27. Baltussen, E.; Sandra, P.; David, F.; Janssen, H. G.; Cramers, C.; Anal. Chem. 1999 71, 5213.

28. Hernandez-Borges, J.; Borges-Miquel, T. M.; Rodríguez-Delgado, M. A.; Cifuentes, A.; J. Chromatogr., A 2007, 1153, 214.

29. Mendiola, J. A.; Herrero, M.; Cifuentes, A.; Ibañez, E.; J. Chromatogr., A 2007, 1152, 234.

30. Carabias-Martínez, R.; Rodríguez-Gonzalo, E.; Revilla-Ruiz, P.; Hernández-Méndez; J.; J. Chromatogr., A 2005, 1089, 1.

31. Camel, V.; Trends Anal. Chem. 2000, 19, 229.

32. Lambropoulou, D. A.; Albanis, T. A.; Anal. Bional. Chem. 2007, 389, 1663.

33. Majors, R. E.; LC GC Eur. 2007, 25, 436.

34. http://www.allbusiness.com/agriculture-forestry-fishing-hunting/9537271.html, acessada em Junho 2008.

35. Čajka, T.; Hajšlová, J.; J. Chromatogr., A 2004, 1058, 251.

36. Zrostiloková, J.; Hajšlová, J.; Čajka, T.; J. Chromatogr., A 2003, 1019 , 173.

37. Fussel, R. J.; Addie, K. J.; Reynolds, S. L.; Wilson, M. F.; J. Agric. Food Chem. 2002, 50, 441.

38. Arrebola, F. J.; Martínez-Vidal, J. L.; Mateu-Sánchez, M.; ÁlvarezCastellón, F. J.; Anal. Chim. Acta 2003, 484, 167.

39. Patel, K.; Fussell, R. J.; Goodall, D. M.; Keely, B. J.; Food Addit. Contam. 2004, 21, 658.

40. Pang, G. F.; Fan, C. L.; Liu, Y. M.; Cao, Y. Z.; Zhang, J. J.; Fu, B. L.; Li, X. M.; Li, Z. Y.; Wu, Y. P.; Food Addit. Contam. 2006, 23, 777.

41. Maštovská, K.; Lehotay, S. J.; J. Chromatogr., A 2004, 1040, 259.

42. Pihlström, T.; Blomkvist, G.; Friman, P.; Pagard, U.; Österdahl, B. G.; Anal. Bional. Chem. 2007, 389, 1773.

43. Lehotay, S. J.; Lightfield, A. R.; Harman-Fetcho, J. A.; Donoghue, D. J.; J. Agric. Food Chem. 2001, 49, 4589.

44. Cook, J.; Becket, M. P.; Reliford, B.; Hammock, W.; Engel, M.; J. AOAC Int. 2001, 82, 1419.

45. Analytical Methods for Pesticide Residues in Foodstuffs, General Inspectorate for Health Protection, $6^{\text {th }}$ ed., The Hage, 1996.

46. Stan, H. J.; J. Chromatogr., A 2000, 892, 347.

47. Pizzutti, I. R.; Kok, A.; Zanella, R.; Adaime, M. B.; Hiemstra, M.; Wickert, C.; Prestes, O. D.; J. Chromatogr., A 2007, 1142, 123.

48. Schenck, F. J.; Brown, A. N.; Podhorniak, L. V.; Parker, A.; Reliford, M.; Wong, J. W.; J. AOAC Int. 2008, 91, 422.

49. Koesukwiwat, U.; Sanguankaew, K.; Leepipatpiboon, N.; Anal. Chim. Acta 2008, 626, 10.

50. Andersson, A.; Pålsheden, H.; Fresenius J. Anal Chem 1991, 339, 365.

51. Saito, Y.; Kodama, S.; Matsunaga, A.; Yamamoto, A.; J. AOAC Int. 2004, 87, 1356.

52. Ueno, E.; Oshima, H.; Saito, I.; Matsumoto, H.; Yoshimura, Y.; Nakazawa, H.; J. AOAC Int. 2004, 87, 1003.

53. Hyötyläinen, T.; J. Chromatogr., A 2008, 1186, 39.

54. Beyer, A.; Biziuk, M.; Food Chem. 2008, 108, 669.
55. Martinez Vidal, J. L.; Garrido Frenich, A.; Pesticides Analysis in Biotechnology, Humana Press: USA, 2005.

56. Trihn, A.; The Reporter 2006, 19, 12.

57. Shimelis, O.; Yang, Y.; Sternerson, K.; Kaneko, T.; Ye, M.; J. Chromatogr., A 2007, 1165, 18.

58. Erney, D. R.; Gillespie, A. M.; Gilvydis, D. M.; Poole, C. F.; J. Chromatogr., A 1993, 638, 57

59. Kruve, A.; Künnapas, A.; Herodes, K.; Leito, I.; J. Chromatogr., A 2008, 1187, 58.

60. Anastassiades, M.; Maštovská, K.; Lehotay, S. J.; J. Chromatogr., A. 2003, 1015, 163.

61. Kirchner, M.; Húšková, R.; Matisová, E.; Mocák, J.; J. Chromatogr., A 2008, 1186, 271.

62. Lehotay, S. J.; Maštovská, K.; Lightfield, A. R.; J. AOAC Int. 2005, 88, 615.

63. Angioni, A.; Garau, V. C.; Del Real, A. A.; Melis, M.; Minelli, E. V.; Tuberoso, C.; Cabras, P.; J. Agric. Food Chem. 2003, 51, 6761.

64. Di Muccio, A.; Dommarco, R.; Barbini, D. A.; Santilio, A.; Girolimetti, S.; Ausili, A.; Ventriglia, M.; Generali, T.; Vergori, L.; J. Chromotogr., A 1993, 643, 363.

65. Gilvydis, D. M.; Walters, S. M.; J. AOAC Int. 1991, 74, 830.

66. Lehotay, S. J.; Kok, A.; Hiemstra, M.; Bodegraven, P.; J. AOAC Int. 2005, 88, 595.

67. Lehotay, S. J.; Maštovská, K.; Yun, S. J.; J. AOAC Int. 2005, 88, 630.

68. Kroon, M.; Rensen, P.; Prestes, O. D.; Adaime, M. B.; Zanella, R.; Kok, A.; Pizzutti, I. R.; Livro de Resumos, $1^{\text {st }}$ Latin American Pesticide Residue Workshop, Santa Maria, Brasil, 2007.

69. Kolberg, D. I. S.; Tese de Doutorado, Universidade Federal de Santa Maria, Brasil, 2007.

70. Li, L.; Xu, Y.; Pan, C.; Zhou, Z.; Jiang, S.; Liu, F.; J. AOAC Int. 2007, 90, 1387.

71. Walorczyk, S.; J. Chromatogr., A 2007, 1165, 200.

72. Hernández-Borges, J.; Borges-Miquel, T. M.; Rodríguez-Delgado, M. A.; Cifuentes, A.; J. Chromatogr., A 2007, 1153, 214.

73. Romero-Gonzalez, R.; Pastor-Montoro, E.; Martínez-Vidal, J. L.; Rapid Commun. Mass Spectrom. 2006, 20, 2701.

74. Alder, L.; Greulich, K.; Kempe, G.; Vieth, B.; Mass Spectrom. Rev. 2006, $25,838$.

75. Leandro, C. C.; Fussell, R. J.; Keely, B. J.; J. Chromatogr., A 2005, 1085, 207.

76. Chiaradia, M. C.; Collins, C. H.; Jardim, I. C. S. F.; Quim. Nova 2008, $31,623$.

77. Fernández-Alba, A. R.; Chromatographic - Mass Spectrometry Food Analysis for Trace Determination of Pesticide Residues, Elsevier: Amsterdam, 2005.

78. Mercer, G. E.; J. AOAC Int. 2005, 88, 1452.

79. Beguin, S.; Jadas-Hëcart, A.; Tabet, J. C.; J. Mass Spectrom. 2006, 41, 1304.

80. Garrido-Frenich, A.; Gonzalez-Rodriguez, I.; Arrebola, F. J.; MarinezVidal, J. L.; Anal. Chem. 2005, 77, 4640.

81. Martinez-Vidal, J. L.; Arrebola, F. J.; Mateu-Sanchez, M.; Rapid Commun. Mass Spectrom. 2002, 16, 1106.

82. Lesueur, C. ; Knittl, P.; Gartner, M.; Mentler, A.; Fuerhacker, M.; Food Control 2007, 19, 906.

83. Payá, P.; Anastassiades, M.; Mack, D.; Sigalova, I.; Tasdelen, B.; Oliva, J.; Barba, A.; Anal. Bional. Chem. 2007, 389, 1697.

84. Libin, L.; Hashi, Y.; Yaping, Q.; Haixia, Z.; Jinming, L.; Chin. J. Anal. Chem. 2006, 34, 783.

85. http://www.thermo.com/eThermo/CMA/PDFs/Articles/ articlesFile_1596, acessada em Julho 2008.

86. Nguyen, T. D.; Yu, J. E.; Lee, D. M.; Lee, G. H.; Food Chem. 2008, 110, 207.

87. Okihashi, M.; Kitagawa, Y.; Akutsu, K.; Obana, H.; Tanaka, Y.; J. Pest. 
Sci. 2005, 30, 368 .

88. Nguyen, T. D.; Lee, B. S.; Lee, B. R.; Lee, G. H.; Rapid Commun. Mass Spectrom. 2007, 21, 3115.

89. Bolaños, P. P.; Moreno, J. L. F.; Shtereva, D. D.; Frenich, A. G.; Vidal, J. L. M.; Rapid Commun. Mass Spectrom. 2007, 21, 2282.

90. Căjka, T.; Maštovská, K.; Lehotay, S. J.; Hajšlová, J.; J. Sep. Sci. 2005, $28,1048$.

91. Stenerson, K.; Wolford, R.; Shimelis, O.; The Reporter 2006, $24,3$.

92. Wang, J. H.; Zhang, Y. B.; Wang, X. L.; J. Sep. Sci. 2006, 29, 2330.

93. Hercegová, A.; Dömötörová, M.; Kružlicová, D.; Matisová, E.; J. Sep. Sci. 2006, 29, 1102.

94. Cajka, T.; Hajslova, J.; Lacina, O.; Mastovska, K.; Lehotay, S.; J. Chromatogr., A 2008, 1186, 281.

95. Okihashi, M.; Takatori, S.; Kitagawa, Y.; Tanaka, Y.; J. AOAC Int. 2007, 90, 1165

96. Lehotay, S.; J. AOAC Int. 2007, 90, 485.

97. Mezcua, M.; Ferrer, C.; García-Reyes, J. F.; Martínez-Bueno, M. J.; Sigrist, M.; Fernández-Alba, A. R.; Food Chem. 2008, 112, 221.

98. http://www.thermo.com/eThermo/CMA/PDFs/Articles/ articlesFile_6937.pdf , acessada em Julho 2008.

99. Fernandez-Moreno, J. L.; Garrido-Frenich, A.; Bolaños, P. P.; MartínezVidal, J. L.; J. Mass Spectrom. 2008, 43, 1245.

100. Húšková, R.; Matisová, E.; Kirchner, M.; Chromatographia 2008, 68, 49.

101. Cunha, S.; Lehotay, S. J.; Mastovska, K.; Fernandes, J. O.; Meatriz, M.; Oliveira, P. P.; J. Sep. Sci. 2006, 30, 620.

102. Garrido-Frenich, A.; Martínez-Vidal, J. L.; López-López, T.; CórtesAguado, S.; Martínez-Salvador, I.; J. Chromatogr., A 2004, 1048, 199.

103. Banerjee, K.; Oulkar, D. P.; Dasgupta, S.; Patil, S. B.; Patil, S. H.; Savant, R.; Adsule, P. G.; J. Chromatogr., A 2007, 1173, 98.

104. Leandro, C. C.; Hancock, P.; Fussell, R. J.; Keely, B. J.; J. Chromatogr., A 2006, 1103, 94 .

105. http://www.pharmaasia.com/article-5737, acessada em Julho 2008.

106. Wang, S.; Xu, Y.; Pan, C.; Jiang, S.; Liu, F.; Anal. Bional. Chem. 2007, 387, 673.

107. Romero-González, R.; Garrido-Frenich, A.; Martínez-Vidal, J. L.; Talanta 2008, 76, 211 .

108. Hernando, M. D.; Ferrer, C.; Ulaszewska, M.; Garcia-Reyes, J. F.;
Molina-Díaz, A.; Fernández-Alba, A. R.; Anal. Bional. Chem. 2007, $389,1815$.

109. Lee, J. M.; Park, J. W.; Jang, G. C.; Hwang, K. J.; J. Chromatogr., A 2008, 1187, 25.

110. Lesueur, C.; Gartner, M.; Mentler, A.; Fuerhacker, M.; Talanta 2007, 75, 284.

111. Jeong, M. L.; Zahn, M.; Trinh, T.; Fay, B.; Ma, W.; J. AOAC Int. 2008, 91, 630 .

112. Hernández-Borges, J.; Cabrera, J. C.; Rodríguez-Delgado, M. A.; Hernández-Suarez, E. M.; Saúco, V. G.; Food Chem. 2009, 113, 313.

113. Barakat, A. A.; Badawy, H. M. A.; Salama, E.; Attallah, E.; Maatook, G.; J. Food Agric. Environ. 2007, 5, 97.

114. Martínez-Galera, M.; Gil-Garcia, M. D.; Santiago-Valverde, R.; Talanta 2008, 76, 815.

115. Pan, C.; Zhang, H.; Chen, S.; Xu, Y.; Jiang, S.; Acta Chromatogr. 2006, $17,320$.

116. Plössl, F.; Giera, M.; Bracher, F.; J. Chromatogr., A 2006, 1135, 19.

117. Fagerquist, C. K.; Lightfield, A. R.; Lehotay, S. J.; Anal. Chem. 2005, $77,1473$.

118. Mastovska, K.; Lehotay, S. J.; J. Agric. Food Chem. 2006, 54, 7001.

119. Rensen, P.; Kroon, M.; Prestes, O. D.; Adaime, M. B.; Zanella, R.; Kok, A.; Pizzutti, I. R.; Livro de Resumos, $1^{\text {st }}$ Latin American Pesticide Residue Workshop, Santa Maria, Brasil, 2007, 89.

120. Rensen, P.; Kroon, M.; Prestes, O. D.; Adaime, M. B.; Zanella, R.; Kok, A.; Pizzutti, I. R.; Livro de Resumos, $1^{\text {st }}$ Latin American Pesticide Residue Workshop, Santa Maria, Brasil, 2007, 90.

121. AOAC, Official Method 2007.01: Pesticide residues in foods by acetonitrile extraction and partitioning with magnesium sulphate, AOAC International, 2007.

122. Codex Committee on Pesticide Residues, Codex Document CX/PR 07/39/06: Proposed draft revision of the list of methods for pesticide residue analysis at step 3, Codex Alimentarius, 2007.

123. European Committee for Standardization-CEN, CEN/TC 275 15662:2008: Foods of plant origin - Determination of pesticide residues using GC-MS and/or LC-MS/MS following acetonitrile extraction/partitioning and cleanup by dispersive SPE - QuEChERS-method, European Union, 2008. 